\title{
Oxidative Damage, Inflammation, and Toll-Like Receptor 4 Pathway Are Increased in Preeclamptic Patients: A Case-Control Study
}

\author{
Fabiana C. B. Bernardi, ${ }^{1}$ Francine Felisberto, ${ }^{1}$ Francieli Vuolo, ${ }^{1}$ \\ Fabricia Petronilho, ${ }^{1}$ Daniela R. Souza, ${ }^{2}$ Thais F. Luciano, ${ }^{2}$ Cláudio T. de Souza, ${ }^{2}$ \\ Cristiane Ritter, ${ }^{1}$ and Felipe Dal-Pizzol ${ }^{1}$ \\ ${ }^{1}$ Laboratório de Fisiopatologia Experimental and Instituto Nacional Translacional em Medicina (INCT-TM), \\ Programa de Pós-Graduação em Ciências da Saúde, Unidade Acadêmica de Ciências da Saúde, \\ Universidade do Extremo Sul Catarinense, Avenida Universitária, 1105, 88806-000 Criciúma, SC, Brazil \\ ${ }^{2}$ Laboratory of Exercise Biochemistry and Physiology, Graduate Program in Health Sciences, \\ University of Southern Santa Catarina-UNESC, Criciúma, SC, Brazil
}

Correspondence should be addressed to Felipe Dal-Pizzol, piz@unesc.net

Received 10 February 2012; Revised 24 April 2012; Accepted 7 May 2012

Academic Editor: Neelam Khaper

Copyright (C) 2012 Fabiana C. B. Bernardi et al. This is an open access article distributed under the Creative Commons Attribution License, which permits unrestricted use, distribution, and reproduction in any medium, provided the original work is properly cited.

Problem. There was no direct correlation between plasma and placental oxidative damage parameters and inflammation and evidence of TLR4 pathway activation in the placenta in preeclamptic (PE) patients. Method of Study. 33 PE patients and 33 normotensive pregnant women were included. The maternal section of the placenta and blood were collected to the determination of oxidative damage markers (thiobarbituric acid reactive species and protein carbonyls), inflammatory response (interleukin-6 and myeloperoxidase activity), and activation of the TLR-4-NF-kB pathway. Results. An increase of IL-6 levels in both plasma and placenta was observed, but myeloperoxidase activity was not significantly different comparing the groups. Oxidative damage parameters were increased in plasma and placenta in PE patients. A significant increase of the protein levels of TLR-4 and NF-kB was observed in the placenta. Conclusion. The TLR4-NF-kB pathway is upregulated in PE, probably generating local and systemic inflammatory response that is followed by local and systemic oxidative damage.

\section{Introduction}

Preeclampsia (PE) is a common disorder of human pregnancy in which the normal hemodynamic response to pregnancy is compromised. It remains a leading cause of maternal morbidity and mortality and is associated with a significant increase in perinatal mortality, and both the etiology and pathophysiology of $\mathrm{PE}$ are poorly understood [1].

Several lines of evidence demonstrated that PE is associated with systemic and placental oxidative stress that may be involved in the pathogenesis of PE [2-5]. Lipid peroxides are formed and bind to the lipoproteins and are then transported to distant sites in the body and result in systemic oxidative stress, thus the placenta may be the site of generation of the lipid peroxides [4].

In addition to oxidative stress, inflammatory response occurs in the placenta of women with PE. In vitro studies have shown altered proinflammatory cytokine production by placental tissue/trophoblast cells from women with PE compared to normal pregnant controls [6]. Some studies suggest that placental toll-like receptor 4 (TLR4) could be associated to inflammation in PE patients [7], but studies correlating TLR4 gene polymorphisms and PE yield controversial results [8-10].

In spite of these, to date there was no direct correlation between plasma and placental oxidative damage parameters 
TABLE 1: Major clinical characteristics of women with normotensive pregnancy and preeclampsia.

\begin{tabular}{lccc}
\hline & $\begin{array}{c}\text { Preeclampsia } \\
(n=33)\end{array}$ & $\begin{array}{c}\text { Normal } \\
\text { gestation } \\
(n=33)\end{array}$ & $P$ values \\
\hline $\begin{array}{l}\text { Age (years) } \\
\text { Parity }(n)\end{array}$ & $25 \pm 6$ & $27 \pm 7$ & 0.35 \\
$\begin{array}{l}\text { Gestational age at delivery } \\
\text { (weeks } \pm \text { days) }\end{array}$ & $37.6 \pm 0.7$ & $1.9 \pm 0.8$ & 0.25 \\
$\begin{array}{l}\text { Systolic blood pressure } \\
\text { (mmHg) }\end{array}$ & $150 \pm 12$ & $115 \pm 9$ & 0.03 \\
$\begin{array}{l}\text { Diastolic blood pressure } \\
\text { (mmHg) }\end{array}$ & $98 \pm 5$ & $73 \pm 4$ & 0.002 \\
$\begin{array}{l}\text { Prepregnancy BMI } \\
\text { Birth weight (g) }\end{array}$ & $23 \pm 6$ & $22 \pm 6$ & 0.40 \\
\hline
\end{tabular}

BMI, body mass index.

and inflammation and an evidence of TLR4 pathway upregulation in the placenta of PE patients. Thus, we here correlated several oxidative and inflammatory parameters measured both in plasma and placenta of PE patients. In addition, we investigated the upregulation of TLR4-NF-kB pathway in these patients.

\section{Results}

2.1. Patients. Major clinical characteristics from patients and controls were showed in Table 1 . There were no significant differences between the groups studied in terms of maternal age (25 \pm 6 versus $27 \pm 7$ in control and PE patients, resp.), parity $(2.3 \pm 0.7$ versus $1.9 \pm 0.8$ in control and PE patients, resp.), and gestational age at delivery $(37.6 \mathrm{wks} \pm 8.5$ days versus 36.1 wks \pm 8.4 days in control and PE patients, resp.).

2.2. Inflammatory Markers. To determine if PE is associated with increased local and systemic inflammation plasma and placenta levels of IL-6 were determined. It was observed an increase of IL-6 levels in both plasma and placenta (Figure 1), that was more expressive in placenta (2.8 times versus 5.2 times). Plasma and placenta IL-6 levels were positively correlated $(r=0.89, P<0.001)$. Activated neutrophils are a major source of IL-6 during inflammatory conditions, but MPO activity was not significantly different in the placenta when comparing control to PE patients (Figure 2), nor the leukocyte count was higher in the blood of PE patients $(8560$ \pm 3200 versus $7430 \pm 2690 \mathrm{~mm}^{3}$, PE versus control, $P>$ $0.05)$.

2.3. Oxidative Damage Markers. Both protein carbonyls and TBARS were increased in plasma and placenta in PE patients when compared to control (Figures 3 and 4). The amount of the increase is around to 2 times and is similar in the placenta and in the plasma. In addition, placenta and plasma oxidative damage parameters are positively correlated $(r=$ $0.76, P=0.01$ to TBARS and $r=0.82, P=0.006$ to protein carbonyls).

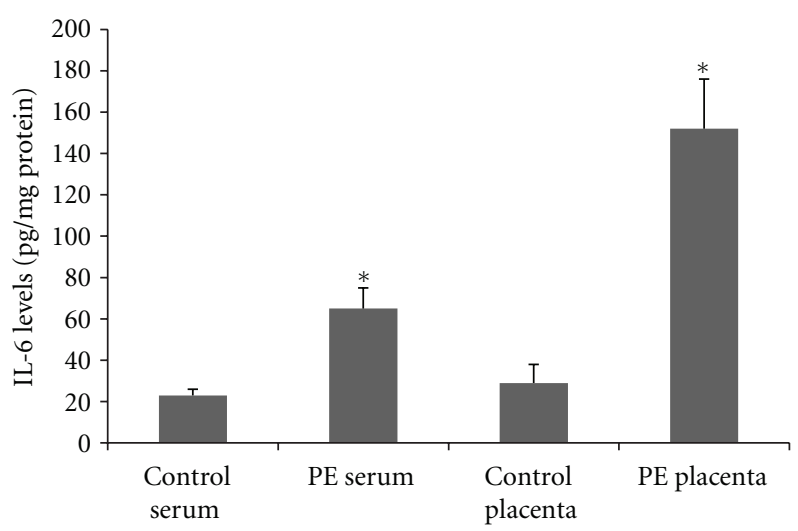

Figure 1: Plasma and placenta levels of interleukin-6 in normal gestation and preeclamptic patients. 33 preeclamptic patients and 33 matched normotensive pregnant women were included and their placenta and peripheral venous blood samples were collected to the determination of interleukin-6 levels using ELISA. * Different from their respective control, $P<0.05$. $\mathrm{PE}=$ pre-eclampsia.

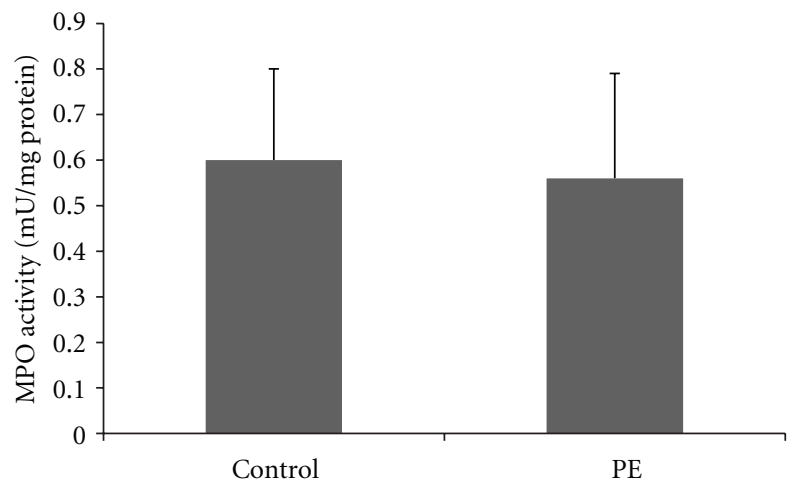

FIGURE 2: Placenta activity of myeloperoxidase in normal gestation and preeclamptic patients.33 preeclamptic patients and 33 matched normotensive pregnant women were included and their placenta was collected to the determination of myeloperoxidase activity using colorimetric assay. PE: pre-eclampsia.

2.4. TLR4-NF-kB Pathway. Trying to determine a pathway related to the observed increase in inflammatory mediators in PE, the protein levels of TLR-4, MyD-88 and NF-kB in the placenta were determined. It was observed a significant increase on both proteins (Figure 5) suggesting a role of this pathway in the inflammatory response observed during PE development.

\section{Discussion}

We demonstrated that systemic inflammation occurs in PE patients, and that the magnitude of this response is higher in the placenta suggesting that placenta could be the primary site of inflammation in this condition. It is also demonstrated local and systemic oxidative damage that could be responsible to part of the alterations observed during the disease process. Interestingly, we could not demonstrate an 


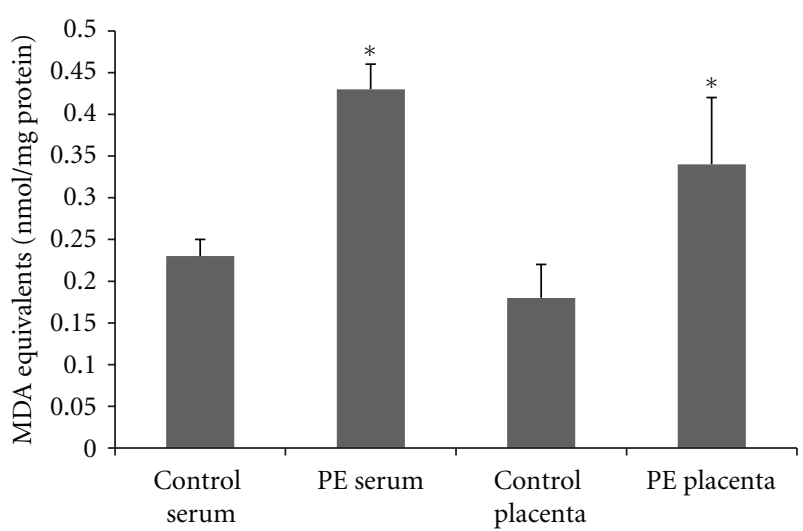

Figure 3: Plasma and placenta levels of thiobarbituric reactive acid species in normal gestation and preeclamptic patients. 33 preeclamptic patients and 33 matched normotensive pregnant women were included and their placenta and peripheral venous blood samples were collected to the determination of thiobarbituric reactive acid species using colorimetric assay. ${ }^{*}$ Different from their respective control, $P<0.05$. $\mathrm{PE}$ : pre-eclampsia.

increase on placenta neutrophils despite the TLR4-MyD88NF-kB pathway seemed to be up-regulated in our sample, suggesting that some other cells are involved in the placenta inflammatory response.

Several reports demonstrated that inflammation occurs during PE development. We recently demonstrated that inflammatory markers are increased in the plasma of $\mathrm{PE}$ patients and this is correlated to oxidative markers and blood pressure, suggesting that these are connected processes and these could be, in part, responsible to the physiologic alterations observed in PE [3]. Exaggerated inflammatory response and imbalance of Th1/Th2 cytokine generation are all considered to be major components of the altered immune response during PE [11-14]. Specifically, levels of IL-6 were previously demonstrated to be elevated in PE patients, compared with age and gestation matched controls [15], but this is not a consensus in the literature [16]. Borekci and colleagues studying mild PE, severe PE, and eclampsia patients did not found differences in serum IL-6 levels when compared to normotensive gestants. However, these authors did demonstrate that higher IL-10 (a prototype anti-inflammatory cytokine) levels are correlated to the occurrence of eclampsia, suggesting, as we demonstrated here, that increased inflammation is an important feature of eclampsia.

Since we could not demonstrate an increase on MPO activity we believed that some other component of the placenta could be responsible to the observed TLR4-MyD88NF-kB upregulation. In this context, pregnant women with antiphospholipid antibodies who are at high risk for preeclampsia markedly enhance trophoblast production of IL8 , MCP- 1 , GRO- $\alpha$, and IL- $1 \beta$ in a TLR4/MyD88-dependent manner in human first trimester trophoblast cells [16]. In addition, it is known that trophoblast cells constitutively produce chemokines that are important for cro-sstalk with local immune cells, and that, in the presence of bacterial and

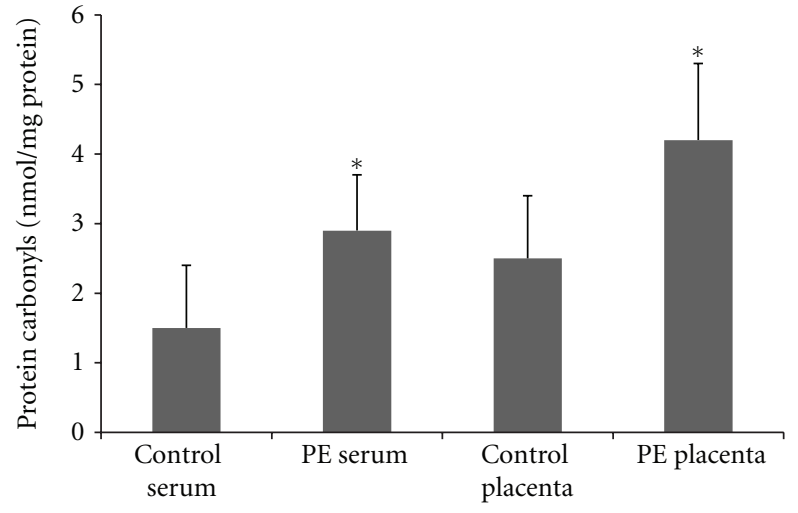

FIGURE 4: Plasma and placenta levels of protein carbonyls in normal gestation and preeclamptic patients. 33 preeclamptic patients and 33 matched normotensive pregnant women were included and their placenta and peripheral venous blood samples were collected to the determination of protein carbonyls using colorimetric assay. ${ }^{*}$ Different from their respective control, $P<0.05 . \mathrm{PE}=$ pre-eclampsia.

viral components, trophoblast generates an inflammatory cytokine/chemokine response [17]. Other potential source of TLR4-NF-kB activation is the decidual cells. It was previously demonstrated higher immunohistochemical staining for IL-6 in decidual cells from preeclamptic versus preterm placentas, suggesting that decidual cell-derived IL-6 may contribute to excess circulating IL-6 levels in PE [18]. In addition, locally produced IL-6 may contribute to an excess of decidual macrophages implicated in shallow extravillous trophoblast invasion of the deciduas [18]. This is consistent with a role of decidual cells on PE-induced inflammation since these cells expressed TLR4 [19]. It is important to note that despite the fact that we could not demonstrate an increase in MPO activity in PE, Gandley, and colleagues suggested that MPO may contribute to the genesis of the disease [20]. In addition, some data did not support the fact that placenta is the source of cytokines during PE [21]. Benyo and colleagues could not detect increased levels of TNF $\alpha$, IL- $1 \beta$, IL- $1 \alpha$, or IL-6 in the placentas from normal term compared with preeclamptic pregnancies, thus despite the fact that IL-6 levels are increased in the circulation from preeclamptic women, the source of this IL- 6 may be activated leukocytes or the maternal endothelium [22].

Pregnancy is characterized by increased generation of ROS. The generation of ROS is enhanced by increased placental mitochondrial activity and the increase in the placental production of superoxide [23]. This increase in the generation of superoxide is also reported to be associated with decreased levels of superoxide dismutase in the placental trophoblast [21]. In addition, reduced perfusion as a result of abnormal placentation is thought to lead to ischemia reperfusion injury to the placenta [23]. Since there is a positive correlation between placenta and systemic oxidative damage parameters, it is reasonable to suppose that these are related processes, and that placenta could release lipid peroxides into the maternal circulation that could contribute 


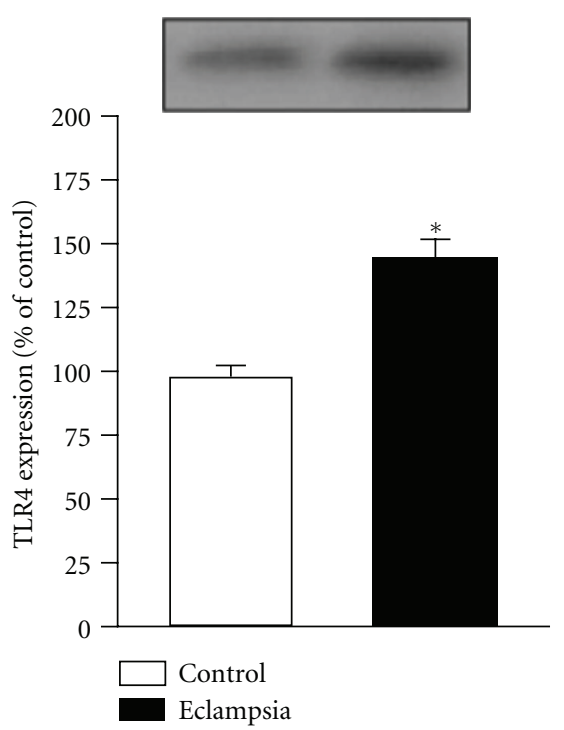

(a)

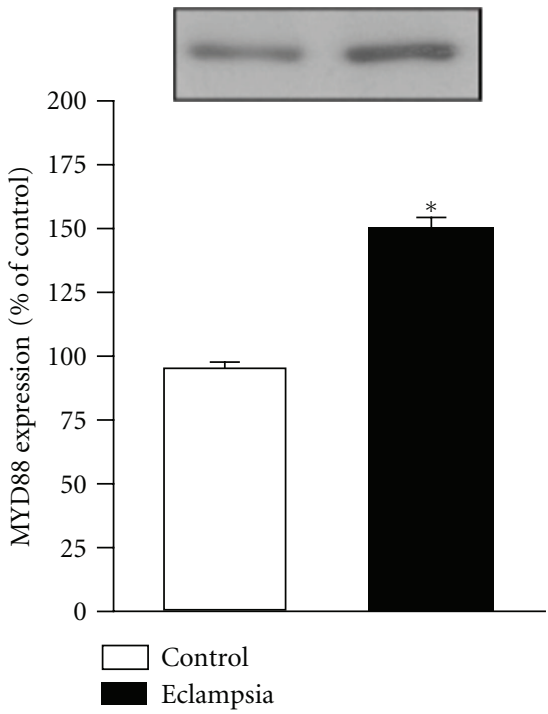

(b)

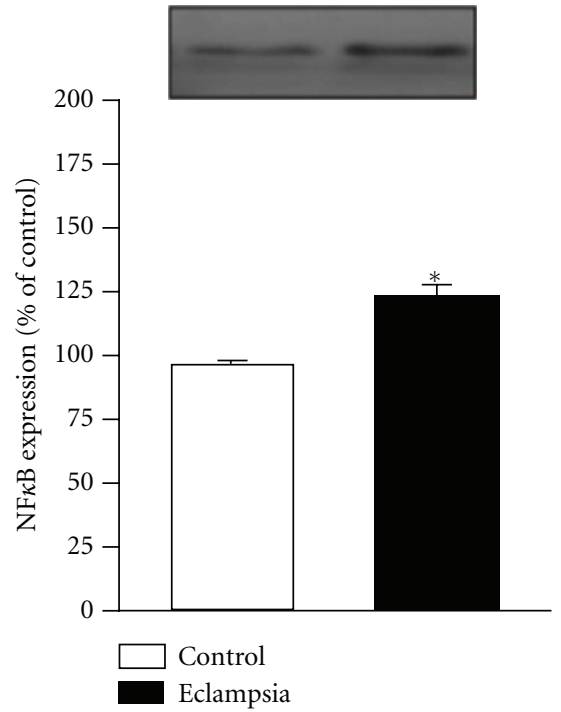

(c)

Figure 5: Placenta protein levels of Toll-like receptor 4, MyD-88 and Nuclear Factor-kB in normal gestation and preeclamptic patients. 33 preeclamptic patients and 33 matched normotensive pregnant women were included and their placenta was collected to the determination of protein levels of Toll-like receptor 4, MyD-88 and nuclear factor-kB using immunoblotting. * Different from their respective control, $P<$ 0.05. PE: pre-eclampsia.

to maternal endothelial cell dysfunction, as previously demonstrated [24].

Some limitations of our study must be pointed-out. Since we collected a single time point of biological samples it is not possible to ascertain a cause-effect relation between TLR4 pathway, inflammation, and oxidative damage, only inferences and correlations. This is a really relevant issue since PE alterations initiate early in the course of gestation, thus determining outcomes at delivery narrows our understanding of the pathophysiology of the disease. Included control patients are in delivery, thus several oxidative and inflammatory alterations associated with delivery are present in our controls, thus adding another control group paired to gestational age, but not at delivery could help us in the understanding of our findings. In addition, it is not possible to ascertain that the nuclear translocation of NF-kB is due to TLR-4 signaling or to some other NF-kB activation pathway. Due to the limited number of patients, it is notpossible to divide $\mathrm{PE}$ patients in early and late, and it seems that these two conditions have some differences $[25,26]$, including issues related to the TLR4 pathway [10]. In addition, we measure only IL-6 that clearly did not reflect several aspects of the inflammatory response during preeclampsis development, and future studies must address this lack of information.

In conclusion, the TLR4-MyD88-NF-kB proteins are upregulated placente from PE patients, and this is related to local and systemic inflammatory response and oxidative damage suggesting that these phenomena could be associated with the development of PE.

\section{Materials and Methods}

4.1. Patients. Informed consent was obtained from all women. Approval for the study was given by the ethics committee of São José Hospital. The study population consisted of 33 consecutive $\mathrm{PE}$ patients and 33 normotensive pregnant women seen for their prenatal care, from January 31 and December 31 2009, at the São José Hospital, Obstetrics and Gynecology Department, Criciúma, Brazil, and admitted to cesarean delivery. Preeclampsia was diagnosed as an increase in diastolic blood pressure of $15 \mathrm{mmHg}$ and systolic blood pressure of $30 \mathrm{mmHg}$ at two measurements at least $4 \mathrm{~h}$ apart compared with BP obtained before 20 weeks of gestation and proteinuria $>0.3 \mathrm{~g} / 24 \mathrm{~h}$ in the absence of urinary tract infection [27]. Women with ruptured membranes, multiple pregnancy, medical complications including autoimmune disorders, diabetes mellitus, inflammatory conditions (including chorioamnionitis), and cases of chronic hypertension with superimposed preeclampsia were not included in this study. Control patients were matched with those with preeclampsia for maternal age, gestational age at delivery, and gestational age at blood sampling. Fasting peripheral venous blood samples obtained at the same gestational age in both groups into heparinized vacutainer tubes. The maternal section of the placenta was obtained in the postpartum period, approximately at the same time of blood sampling, and washed with saline solution to remove blood cells. All biological specimens were immediately putt in liquid nitrogen and then stored at $-80^{\circ} \mathrm{C}$ until assayed.

4.2. Oxidative Stress Markers. The formation of thiobarbituric acid reactive species (TBARS) during an acid-heating reaction was measured as an index of oxidative stress as previously described [28]. Briefly, the samples from placenta and serum were mixed with $1 \mathrm{~mL}$ of trichloroacetic acid $10 \%$ and $1 \mathrm{~mL}$ of thiobarbituric acid $0.67 \%$ and then heated in a boiling water bath for 15 minutes with the addition of butylated hydroxytoluene. Malondialdehyde equivalents 
were determined by the absorbance at $535 \mathrm{~nm}$ using 1,1,3,3tetramethoxypropane as an external standard. Results were expressed as malondialdehyde equivalents per milligram of protein.

The oxidative damage to proteins was assessed by the determination of carbonyl groups based on the reaction with dinitrophenylhydrazine as previously described [29]. Briefly, proteins were precipitated by the addition of $20 \%$ trichloroacetic acid and redissolved in dinitrophenylhydrazine, and the absorbance was read at $370 \mathrm{~nm}$.

4.3. Inflammatory Markers. Interleukin (IL)-6 was determined as a prototype proinflammatory cytokine using commercial available kits (PrepoTech, Rocky Hill, NJ, USA) according manufacturer recommendation. One fragment of the placenta was homogenized in extraction solution containing aprotinin. Briefly, the capture antibody (concentration provided by the manufacturer) was diluted in phosphate-buffered saline (PBS), added to each well and left overnight at $4^{\circ} \mathrm{C}$. The plate was washed four times with PBS and $0.05 \%$ Tween 20 (Sigma, St. Louis, MO, USA). The plate was blocked with $1 \%$ bovine serum albumin and incubated for $1 \mathrm{~h}$ at room temperature before washing four times with PBS and $0.05 \%$ Tween 20. The samples and standards were added, and the plate was incubated overnight at $4^{\circ} \mathrm{C}$. After washing the plate, detection antibody (concentration provided by the manufacturer) diluted in PBS was added. The plate was incubated for $2 \mathrm{~h}$ at room temperature. After washing the plate, streptavidin (DuoSet R\&D Systems, Minneapolis, MN, USA) was added and the plate was incubated for $30 \mathrm{~min}$. At last, color reagent $o$ phenylenediamine (Sigma) was added to each well and the reaction was allowed to develop in the dark for $15 \mathrm{~min}$. The reaction was stopped with the addition of $1 \mathrm{M} \mathrm{H}_{2} \mathrm{SO}_{4}$ to each well. The absorbance was read on a plate reader at $492 \mathrm{~nm}$ wave length.

As an index of neutrophil infiltration, we measured myeloperoxidase (MPO) activity in tissue homogenate. Tissue was homogenized $(50 \mathrm{mg} / \mathrm{mL})$ in $0.5 \%$ hexadecyltrimethylammonium bromide in $10 \mathrm{mM} 3-\mathrm{N}$-morpholinopropanesulfonic acid and centrifuged at 15,000 g for $40 \mathrm{mins}$. The suspension was then sonicated three times for 30 csecs. An aliquot of supernatant was mixed with a solution of $1.6 \mathrm{mM}$ tetramethylbenzidine and $1 \mathrm{mM}$ hydrogen peroxide. Activity was measured spectrophotometrically as the change in absorbance at $650 \mathrm{~nm}$ at $37^{\circ} \mathrm{C}$, using a SpectraMax Microplate Reader [30]. Results are expressed as milliunits of MPO activity per milligram of protein.

Blood leucocytes counts were obtained in the routine analyses of the biochemistry laboratory from our hospital using a SYSMEX analyser, model XT-1800i.

4.4. TLR-4-MyD88-NF-kB Pathway. The content of TLR4, MyD88, and NF-kB protein in placenta was quantified by immunoblotting and expressed as \% comparing to control patients. NF-kB determination was performed in nuclear extracts from placenta. The samples were homogenized in extraction buffer at $4^{\circ} \mathrm{C}$ with a Polytron PTA
20S generator (Brinkmann Instruments model PT 10/35) operated at maximum speed for $30 \mathrm{~s}$. The extracts were centrifuged at $11000 \mathrm{rpm}$ and $4^{\circ} \mathrm{C}$ in a Beckman $70.1 \mathrm{Ti}$ rotor (Palo Alto, CA, USA) for $40 \mathrm{~min}$ to remove insoluble material, and the supernatants of these tissues were used for protein quantification, using the Bradford method. Extracted proteins were denatured by boiling in Laemmli sample buffer containing $100 \mathrm{mM}$ DTT, run on SDS-PAGE, and transferred to nitrocellulose membranes. The membranes were blocked, probed with anti-TLR or anti-NF-kB antibodies (Santa Cruz Biotechnology, Inc, CA, USA) or anti-MyD88 antibodies (Cell Signaling, US) and developed as described previously [31]. The blots were exposed to preflashed Kodak XAR film with Cronex Lightning Plus intensifying screens at $-80^{\circ} \mathrm{C}$ for $12-48 \mathrm{~h}$. Intensities of bands were quantitated by optical desitometry (Scion Image software, ScionCorp, Frederick, MD, USA) of the developed autoradiography.

Statistical Analyses. Standard descriptive statistics were calculated to examine baseline characteristics of the study population. Continuous variables with normal distribution were presented as mean \pm standard deviation and compared by $t$-Student test. Continuous variables with a non-normal distribution were reported as median (25\%-75\% interquartile range) and compared using Mann-Whitney $U$ test or Kruskal-Wallis test, as appropriate. Categorical variables were presented as absolute numbers (frequency percentages) and analyzed by Chi-square test (with Yates correction where applicable). A two-tailed $P$-value $<0.05$ was considered statistically significant.

\section{References}

[1] S. A. Friedman, R. N. Taylor, and J. M. Roberts, "Pathophysiology of preeclampsia," Clinics in Perinatology, vol. 18, no. 4, pp. 661-682, 1991.

[2] A. M. Roggensack, Y. Zhang, and S. T. Davidge, "Evidence for peroxynitrite formation in the vasculature of women with preeclampsia," Hypertension, vol. 33, no. 1 I, pp. 83-89, 1999.

[3] F. Bernardi, F. Guolo, T. Bortolin, F. Petronilho, and F. DalPizzol, "Oxidative stress and inflammatory markers in normal pregnancy and preeclampsia," Journal of Obstetrics and Gynaecology Research, vol. 34, no. 6, pp. 948-951, 2008.

[4] J. Vanderlelie, K. Venardos, V. L. Clifton, N. M. Gude, F. M. Clarke, and A. V. Perkins, "Increased biological oxidation and reduced anti-oxidant enzyme activity in pre-eclamptic placentae," Placenta, vol. 26, no. 1, pp. 53-58, 2005.

[5] Y. Wang, S. W. Walsh, and H. H. Kay, "Placental lipid peroxides and thromboxane are increased and prostacyclin is decreased in women with preeclampsia," American Journal of Obstetrics and Gynecology, vol. 167, no. 4 I, pp. 946-949, 1992.

[6] S. Zhao, Y. Gu, Q. Dong, R. Fan, and Y. Wang, "Altered interleukin-6 receptor, IL-6R and gp130, production and expression and decreased SOCS-3 expression in placentas from women with pre-eclampsia," Placenta, vol. 29, no. 12, pp. 1024-1028, 2008.

[7] M. K. Yeon, R. Romero, Y. O. Seo et al., "Toll-like receptor 4: a potential link between 'danger signals,' the innate immune system, and preeclampsia?" American Journal of Obstetrics and Gynecology, vol. 193, no. 3, pp. 921-927, 2005. 
[8] B. B. van Rijn, A. Franx, E. A. P. Steegers et al., "Maternal TLR4 and NOD2 gene variants, pro-inflammatory phenotype and susceptibility to early-onset preeclampsia and HELLP syndrome," PLoS One, vol. 3, no. 4, Article ID e1865, 2008.

[9] A. Molvarec, M. Jermendy, M. Kovács et al., "Toll-like receptor 4 gene polymorphisms and preeclampsia: lack of assocaition in a Caucasian population," Hypertension Research, vol. 31, no. 5, pp. 859-864, 2008.

[10] F. Xie, Y. Hu, S. E. Turvey et al., "Toll-like receptors 2 and 4 and the cryopyrin inflammasome in normal pregnancy and preeclampsia," An International Journal of Obstetrics and Gynaecology, vol. 117, no. 1, pp. 99-108, 2010.

[11] C. W. G. Redman, G. P. Sacks, and I. L. Sargent, "Preeclampsia: an excessive maternal inflammatory response to pregnancy," American Journal of Obstetrics and Gynecology, vol. 180, no. 2 I, pp. 499-506, 1999.

[12] Y. Jonsson, M. Rubèr, L. Matthiesen et al., "Cytokine mapping of sera from women with preeclampsia and normal pregnancies," Journal of Reproductive Immunology, vol. 70, no. 1-2, pp. 83-91, 2006.

[13] G. M. Stirrat, "Pregnancy and immunity," British Medical Journal, vol. 308, no. 6941, pp. 1385-1386, 1994.

[14] T. G. Wegmann, H. Lin, L. Guilbert, and T. R. Mosmann, "Bidirectional cytokine interactions in the maternal-fetal relationship: is successful pregnancy a TH2 phenomenon?" Immunology Today, vol. 14, no. 7, pp. 353-356, 1993.

[15] G. S. Vince, P. M. Starkey, R. Austgulen, D. Kwiatkowski, and C. W. G. Redman, "Interleukin-6, tumour necrosis factor and soluble tumour necrosis factor receptors in women with preeclampsia," British Journal of Obstetrics and Gynaecology, vol. 102, no. 1, pp. 20-25, 1995.

[16] M. J. Mulla, J. J. Brosens, L. W. Chamley et al., "Antiphospholipid antibodies induce a pro-inflammatory response in first trimester trophoblast via the TLR4/MyD88 pathway," American Journal of Reproductive Immunology, vol. 62, no. 2, pp. 96-111, 2009.

[17] V. M. Abrahams, I. Visintin, P. B. Aldo, S. Guller, R. Romero, and G. Mor, "A role for TLRs in the regulation of immune cell migration by first trimester trophoblast cells," Journal of Immunology, vol. 175, no. 12, pp. 8096-8104, 2005.

[18] C. J. Lockwood, C. F. Yen, M. Basar et al., "Preeclampsiarelated inflammatory cytokines regulate interleukin-6 expression in human decidual cells," American Journal of Pathology, vol. 172, no. 6, pp. 1571-1579, 2008.

[19] K. N. Evans, L. Nguyen, J. Chan et al., "Effects of 25-hydroxyvitamin D3 and 1,25-dihydroxyvitamin D 3 on cytokine production by human decidual cells," Biology of Reproduction, vol. 75, no. 6, pp. 816-822, 2006.

[20] R. E. Gandley, J. Rohland, Y. Zhou et al., "Increased myeloperoxidase in the placenta and circulation of women with preeclampsia," Hypertension, vol. 52, no. 2, pp. 387-393, 2008.

[21] B. Borekci, H. Aksoy, R. A. Al, B. Demircan, and S. Kadanali, "Maternal serum interleukin-10, interleukin-2 and interleukin-6 in pre-eclampsia and eclampsia," American Journal of Reproductive Immunology, vol. 58, no. 1, pp. 56-64, 2007.

[22] D. F. Benyo, A. Smarason, C. W. G. Redman, C. Sims, and K. P. Conrad, "Expression of inflammatory cytokines in placentas from women with preeclampsia," Journal of Clinical Endocrinology and Metabolism, vol. 86, no. 6, pp. 2505-2512, 2001.

[23] S. Gupta, N. Aziz, L. Sekhon et al., "Lipid peroxidation and antioxidant status in preeclampsia: a systematic review," Obstetrical and Gynecological Survey, vol. 64, no. 11, pp. 750759, 2009.
[24] M. T. M. Raijmakers, R. Dechend, and L. Poston, "Oxidative stress and preeclampsia: rationale for antioxidant clinical trials," Hypertension, vol. 44, no. 4, pp. 374-380, 2004.

[25] R. Aliyazicioglu, S. Guven, A. Mentese et al., "Serum anticarbonic anhydrase II antibodies and oxidant-antioxidant balance in pre-eclampsia," American Journal of Reproductive Immunology, vol. 66, no. 4, pp. 297-303, 2011.

[26] J. L. Van Der Merwe, D. R. Hall, C. Wright, P. Schubert, and D. Grové, "Are early and late preeclampsia distinct subclasses of the diseasewhat does the placenta reveal," Hypertension in Pregnancy, vol. 29, no. 4, pp. 457-467, 2010.

[27] ACOG Committee on Practice Bulletins, Obstetrics, "ACOG practice bulletin. Diagnosis and management of preeclampsia and eclampsia," Obstetrics \& Gynecology, vol. 99, no. 1, pp. 159-167, 2002.

[28] H. H. Draper and M. Hadley, "Malondialdehyde determination as index of lipid peroxidation," Methods in Enzymology, vol. 186, pp. 421-431, 1990.

[29] R. L. Levine, J. A. Williams, E. R. Stadtman, and E. Shacter, "Carbonyl assays for determination of oxidatively modified proteins," Methods in Enzymology, vol. 233, pp. 346-357, 1994.

[30] L. Liaudet, J. G. Mabley, F. G. Soriano et al., "Inosine reduces systemic inflammation and improves survival in septic shock induced by cecal ligation and puncture," American Journal of Respiratory and Critical Care Medicine, vol. 164, no. 7, pp. 1213-1220, 2001.

[31] C. T. De Souza, A. L. Gasparetti, M. Pereira-da-Silva et al., "Peroxisome proliferator-activated receptor $\gamma$ coactivator-1dependent uncoupling protein-2 expression in pancreatic islets of rats: a novel pathway for neural control of insulin secretion," Diabetologia, vol. 46, no. 11, pp. 1522-1531, 2003. 


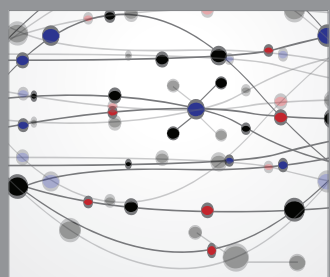

The Scientific World Journal
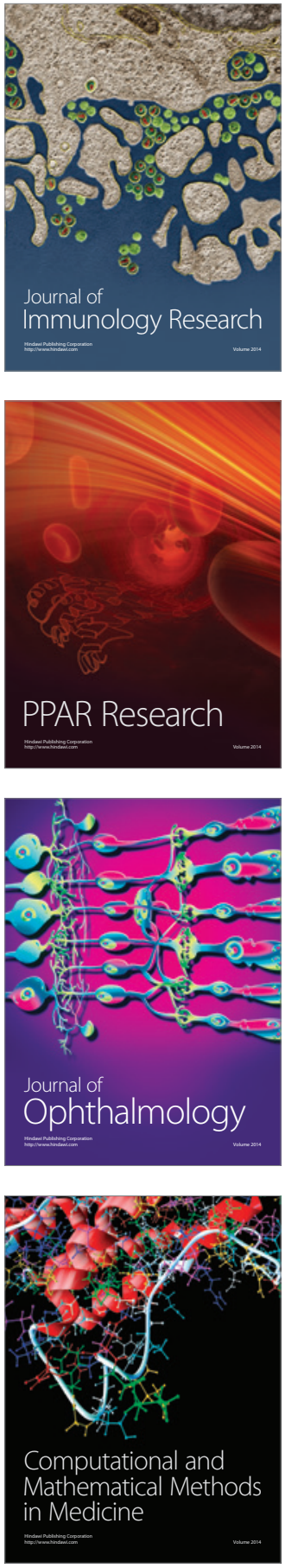

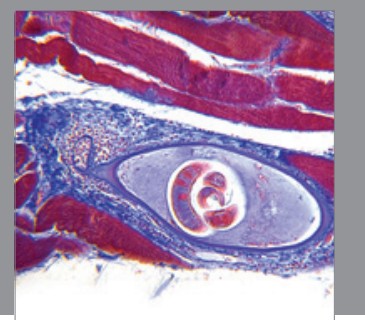

Gastroenterology

Research and Practice
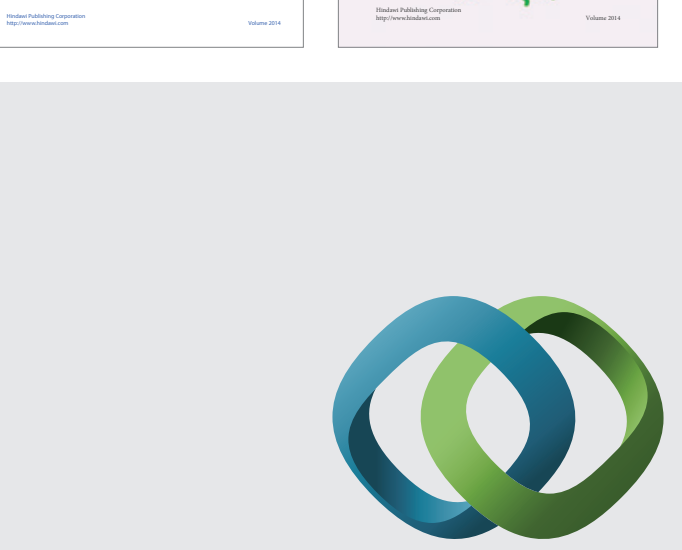

\section{Hindawi}

Submit your manuscripts at

http://www.hindawi.com
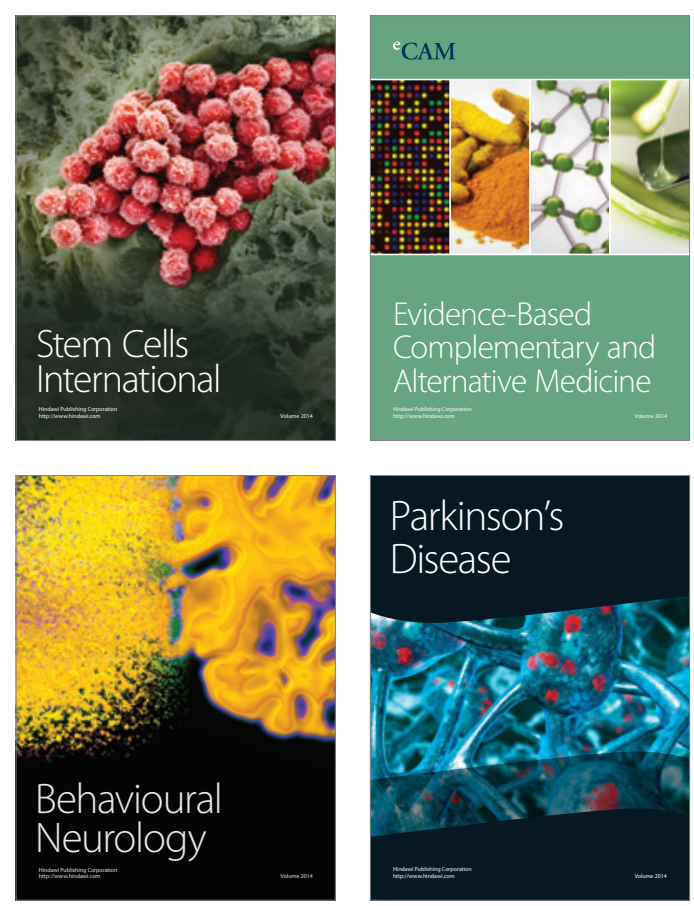

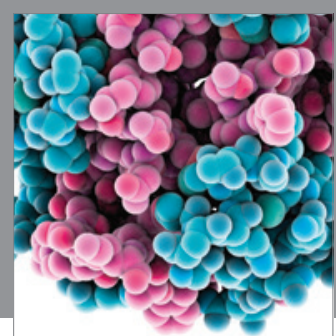

Journal of
Diabetes Research

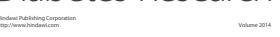

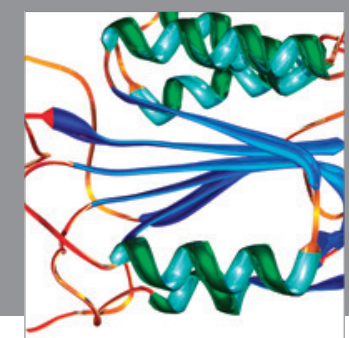

Disease Markers
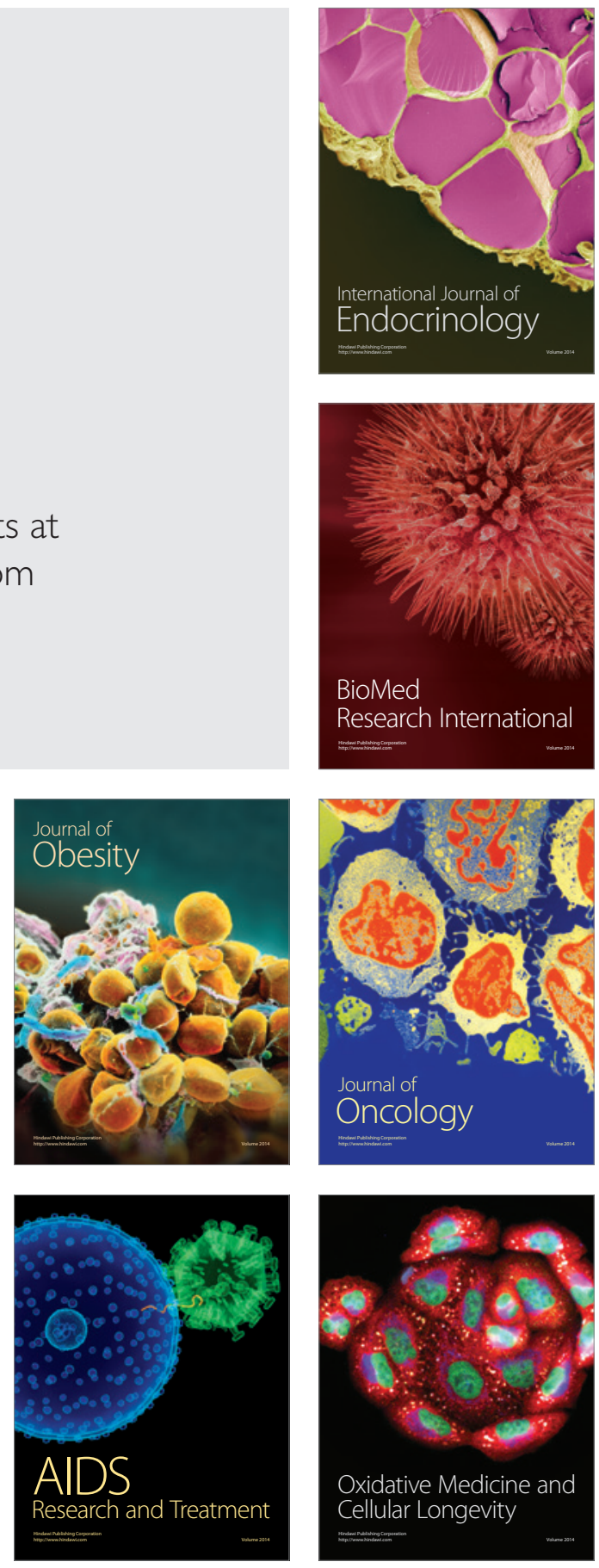